\title{
Temperature study of magnetic resonance spectra of co-modified (Co,N)-TiO 2 nanocomposites
}

\author{
Nikos Guskos ${ }^{1,2}$, JANusz TyPeK $^{2}$, GrZegorz ZolnierkiewiCZ ${ }^{2 *}$, AleKSANDER Guskos $^{2}$, \\ PAWEl BerCZYNSKi ${ }^{2}$, Diana Dolat ${ }^{3}$, Sylwia Mozia ${ }^{3}$, Konstantinos Aidinis ${ }^{4}$, \\ KONRAD KRUK ${ }^{5}$, ANTONI W. MORAWSKI ${ }^{3}$ \\ ${ }^{1}$ Department of Solid State Physics, Faculty of Physics, University of Athens, Panepistimioupolis, GR-157 84 Athens, Greece \\ ${ }^{2}$ Department of Physics, West Pomeranian University of Technology, al. Piastow 48, 70-311 Szczecin, Poland \\ ${ }^{3}$ Department of Chemical and Environmental Engineering, West Pomeranian University of Technology, \\ al. Piastow 17, 70-310 Szczecin, Poland \\ ${ }^{4}$ Department of Electronic, Faculty of Physics, University of Athens, Panepistimioupolis, GR-157 84 Athens, Greece \\ ${ }^{5}$ Faculty of Electrical Engineering, West Pomeranian University of Technology, ul. Sikorskiego 37, 70-313 Szczecin, Poland
}

The $(\mathrm{nCo}, \mathrm{N})-\mathrm{TiO}_{2}(\mathrm{n}=1,5$ and $10 \mathrm{wt} . \%$ of $\mathrm{Co})$ nanocomposites were investigated by magnetic resonance spectroscopy in $4 \mathrm{~K}$ to $290 \mathrm{~K}$ range. Analyses of ferromagnetic/electron paramagnetic resonance (FMR/EPR) spectra in terms of four Callen lineshape components revealed the existence of two types of magnetic centers, one derived from metallic cobalt nanoparticles in superparamagnetic (SPM) phase and the other from cobalt clusters in the $\mathrm{TiO}_{2}$ lattice. Additionally, at low temperature the EPR spectrum arising from $\mathrm{Ti}^{3+}$ ions was also registered. Both relaxations of the Landau-Lifshitz type and the Bloch-Bloembergen type played an important role at high temperature in determining the linewidths and the latter relaxation was prevailing at low temperature. Analysis of the integrated intensity showed that the SPM signal is due to small size FM cobalt nanoparticles while the paramagnetic signal from Co clusters originates from those nanoparticles in which the concentration of magnetic polarons is below the percolation threshold.

Keywords: nano titanium dioxide; electron paramagnetic resonance; photocatalyst

(C) Wroclaw University of Technology.

\section{Introduction}

Titanium dioxide $\left(\mathrm{TiO}_{2}\right)$, a nontoxic, cheap, resistant to photo-corrosion, and highly oxidative material, is the most widely used in semiconductorbased heterogeneous photocatalyst [1]. It allows the sunlight to be used for the destruction of toxic pollutants, enables selective redox transformations in certain organic compounds, and is used in the conversion of solar energy to electric power [2-5]. A relatively wide band gap of $\mathrm{TiO}_{2}$ (above $3 \mathrm{eV}$ ) is an obvious disadvantage for photocatalytic applications, preventing an effective absorption of the visible part of solar radiation. To remedy this, $\mathrm{TiO}_{2}$ was doped with both transition metals (e.g. Fe, Co, $\mathrm{Ni}, \mathrm{Cr}, \mathrm{Cu}, \mathrm{V}$ ) and non-metals (e.g. N, S, C, B)

*E-mail: gzolnierkiewicz@ zut.edu.pl impurities [6]. On the one hand, the doping has decreased the photo-threshold energy for $\mathrm{TiO}_{2}$ but on the other hand it also reduced its overall activity through introduction of recombination centres for electrons and holes. Doping also brought one unexpected result as its magnetic property is concerned: $\mathrm{TiO}_{2}$ showed ferromagnetism (FM) at room temperature (RT).

The first report on room temperature ferromagnetism (RTFM) in $\mathrm{TiO}_{2}$ thin films was published in 2001 by Matsumoto et al. [7]. Since that time a lot of research has been carried out on RTFM in $\mathrm{TiO}_{2}$ samples having very different forms (thin film, nanopowder, nanocrystal, nanorod, nanobelt, etc.). The main motivation of such huge interest seems to be the potential application of these materials in microelectronic devices based on the spin degree of freedom of an electron (spintronics). 
Earlier theoretical works by Dietl et al. [8] indicated that the introduction of $\mathrm{Mn}$ into $\mathrm{GaN}, \mathrm{GaP}$ as well as $\mathrm{ZnO}$ and other oxide materials could produce RTFM. The proposed model, called the Free Carrier Mediated Exchange Model, explained the FM by the exchange interaction between carriers and the localized spins, i.e. the magnetic property was mediated by the charge carriers of the materials. As this particular model can be applied only to materials having high hole concentration, it is not suitable for low carrier concentration materials, like $\mathrm{TiO}_{2}$. The double exchange mechanism, modelled by Sato et al. [9], is more suitable in that case. According to this model the magnetic ions in different charge states couple with each other by virtual hopping of an extra electron from one ion to the other. As a result, the $3 \mathrm{~d}$ electron in the partially occupied $3 \mathrm{~d}$ orbital of the metal ion is allowed to hop to the $3 \mathrm{~d}$ orbital of the neighbouring metal ion, provided that they have parallel magnetic moments. In a similar model proposed by Coey et al. [10] the FM exchange is mediated by shallow donor electrons that form bound magnetic polarons (BMP), which in turn overlap to create a spin split impurity band. BMP can be formed by an electron trapped in oxygen vacancy and by neighbouring magnetic doped ions. Magnetic ions in different charge states are coupled by virtual hopping of the 'extra' electron from one ion to the other. Since that time many papers have been devoted to the subject of the so-called Diluted Magnetic Semiconductors (DMS) in which non-magnetic semiconductors are doped with magnetic atoms [11]. Typical DMS oxides are: $\mathrm{ZnO}, \mathrm{In}_{2} \mathrm{O}_{3}, \mathrm{TiO}_{2}, \mathrm{SnO}_{2}, \mathrm{CuO}$ and $\mathrm{HfO}_{2}$ [12]. The issue of DMS still remains a highly controversial one. Numerous reports have ascribed the observed RTFM to extrinsic causes (e.g. native or dopant-introduced defects, formation of FM secondary phases, metallic clusters), while a large number of others attributed RTFM to intrinsic causes (e.g. mediated by carriers or intentional defects inside the host semiconductor). Thus, the observed RTFM phenomenon in insulating samples is still a challenge, both for experimentalists and materials science theorists.

This question of intrinsic or extrinsic origin of RTFM is especially difficult to answer in case of magnetic dopants like $\mathrm{Ni}, \mathrm{Fe}$, and $\mathrm{Co}$, which are FM in nature. As a matter of fact RTFM may originate from both types of causes in $\mathrm{Co}: \mathrm{TiO}_{2}$ system. Whether an intrinsic or extrinsic cause is realized in a particular sample depends on many factors. To name a few more important: the type of crystal structure of $\mathrm{TiO}_{2}$ (rutile or anatase), the presence or lack of anatase-rutile junction, the concentration of oxygen vacancies, the growth temperature of $\mathrm{TiO}_{2}$, the temperature and atmosphere (oxygen, vacuum) of annealing, the content and distribution of Co dopant, the presence of secondary phases, the sizes of nanoparticles. Extrinsic origin of RTFM (metallic clusters) can be identified from magnetic measurements by calculation of the magnetic moment per single Co atom (from the saturation magnetization derived from hysteresis loop) or by observation of the temperature dependence of magnetization in zero field cooling (ZFC) and field cooling (FC) modes. For metallic Co clusters the magnetic moment per single Co atom should be similar to what is obtained for pure bulk $\mathrm{Co}$ metal $\left(1.7 \mu_{\mathrm{B}} / \mathrm{Co}\right)$. On the other hand, for $\mathrm{Co}^{2+}$ in octahedral complexes, experimentally observed magnetic moments are in 4 to $5 \mu_{\mathrm{B}} / \mathrm{Co}$ range. If a Co metal cluster can be treated as a magnetic nanoparticle suspended in $\mathrm{TiO}_{2}$ matrix, superparamagnetic (SPM) behavior is expected and can be registered in temperature dependence of magnetization in ZFC mode as magnetization maximum at the so-called blocking temperature $\mathrm{T}_{\mathrm{B}}$. The intrinsic mechanism of RTFM, mostly of the BMP type, was preferred in case of $\mathrm{Co}: \mathrm{TiO}_{2}$ thin films [13-16] and nanoparticles [17-19]. On the other hand, the extrinsic origin (mostly metallic Co clusters) was blamed for RTFM in thin films of $\mathrm{Co}^{-\mathrm{TiO}_{2}}$ [20-22] and nanoparticles [23, 24].

Electron paramagnetic resonance/ferromagnetic resonance (EPR/FMR) is another spectroscopic method to study local magnetic properties of paramagnetic/ferromagnetic substances. Huang et al. [25] studied EPR spectra at RT of $\mathrm{Co}: \mathrm{TiO}_{2}$ nanotubes and recorded a not so broad (peak-to-peak linewidth $\sim 400 \mathrm{G}$ ) EPR line centered at $\mathrm{g}=2.19$ and attributed it to high spin $\mathrm{Co}^{2+}$ ions in an octahedral environment. 
They concluded that the Co atoms should occupy Ti sites in $\mathrm{TiO}_{6}$ octahedra in the layers of titanate nanotubes, giving spectroscopic evidence for the substitution of $\mathrm{Co}^{2+}$ for $\mathrm{Ti}^{4+}$ [25]. From additional magnetization study they deduced that RTFM arises from the exchange interaction between $\mathrm{Co}^{2+}$ mediated by oxygen vacancies, and not from Co nanoclusters. Sadanandam et al. [26] also studied the Co doped $\mathrm{TiO}_{2}$ photocatalysts by EPR spectroscopy at RT. They obtained a strong EPR signal, which is normally the result of high spin $\mathrm{Co}^{2+}$ ions on $\mathrm{TiO}_{2}$ surface. Magnetic resonance study at RT of three $(\mathrm{nCo}, \mathrm{N})-\mathrm{TiO}_{2}(\mathrm{n}=1,5$, 10 wt.\% of Co) nanopowder samples was also carried out in our group: Guskos et al. [27] found that the observed spectrum arises from two types of strongly correlated spin systems, thus, the spectrum should be treated as FMR spectrum. In one spin system the magnetic anisotropy has not varied with Co concentration, in the other system the anisotropy has decreased with Co concentration.

In this report, a study of the magnetic resonance spectra of three co-modified ( $\mathrm{nCo}, \mathrm{N})-\mathrm{TiO}_{2}(\mathrm{n}=1$, $5,10 \mathrm{wt} . \%$ of $\mathrm{Co}$ ) nanopowders in the $4 \mathrm{~K}$ to $290 \mathrm{~K}$ temperature range is presented. The FMR spectra will be analyzed in terms of Callen-type components and the temperature dependence of spectral parameters of these components (amplitude, resonance field, two types of linewidths, integrated intensity) will be investigated. The obtained results of the spectroscopic characteristics of $(\mathrm{nCo}, \mathrm{N})-\mathrm{TiO}_{2}$ will be compared with earlier magnetization investigations of the same samples and with previously studied $(\mathrm{nFe}, \mathrm{N})-\mathrm{TiO}_{2}(\mathrm{n}=1,5,10$ wt.\% of $\mathrm{Fe})$ nanocomposites.

\section{Experimental}

The method of sample preparation and detailed characterization of three $(\mathrm{nCo}, \mathrm{N})-\mathrm{TiO}_{2}(\mathrm{n}=1,5$, $10 \mathrm{wt} . \%$ of $\mathrm{Co}$ ) nanocomposites were presented in the literature [28]. Water suspension of an industrial grade amorphous titanium dioxide $\left(\mathrm{TiO}_{2} / \mathrm{A}\right.$, containing amorphous as well as anatase and rutile phases at the ratio of $61.5: 35: 3.5)$ obtained from the sulphate technology supplied by Chemical
Factory Police Inc., Poland, was used as a starting material. $\mathrm{TiO}_{2} / \mathrm{A}$ was introduced into a beaker containing an aqueous solution of $\mathrm{Co}\left(\mathrm{NO}_{3}\right)_{2} \cdot \mathrm{H}_{2} \mathrm{O}$ and stirred for $48 \mathrm{~h}$. After water evaporation, the samples were dried at $80{ }^{\circ} \mathrm{C}$ for $24 \mathrm{~h}$ in oven. Subsequently, the materials were calcined for $4 \mathrm{~h}$ at $800{ }^{\circ} \mathrm{C}$ in an $\mathrm{NH}_{3}$ flow. According to the XRD measurements, the $(\mathrm{nCo}, \mathrm{N})-\mathrm{TiO}_{2}$ photocatalysts consisted of two phases: rutile $\mathrm{TiO}_{2}$ and ternary oxide, namely $\mathrm{CoTiO}_{3}$ [27]. A small amount of metallic Co residues was also observed [27]. The three investigated samples have been designated as $1 \mathrm{Co}, \mathrm{N}-$ $\mathrm{TiO}_{2}, 5 \mathrm{Co}, \mathrm{N}-\mathrm{TiO}_{2}$ and $10 \mathrm{Co}, \mathrm{N}-\mathrm{TiO}_{2}$. Magnetic resonance spectra were obtained on a conventional EPR X-band ( $v=9.4 \mathrm{GHz})$ Bruker E $500 \mathrm{spec}-$ trometer with $100 \mathrm{kHz}$ magnetic field modulation. The measurements were performed in the $4 \mathrm{~K}$ to $290 \mathrm{~K}$ temperature range using an Oxford helium flow cryostat.

\section{Results and discussion}

Fig. 1 presents magnetic resonance spectra of the three investigated co-modified $(\mathrm{nCo}, \mathrm{N})-\mathrm{TiO}_{2}$ nanocomposites registered at different temperatures. The single, broad, intense and asymmetrical line visible in all samples, is clearly recognizable. Such spectrum is typical of the previously registered ones from strongly correlated spin system of agglomerated nanoparticles [29-32]. Additionally, EPR signal (a narrow line at the magnetic field corresponding to g-factor $\sim 2$ ) attributed to isolated trivalent titanium ions was identified at low temperatures. In sample $1 \mathrm{Co}, \mathrm{N}-\mathrm{TiO}_{2}$ this EPR signal was over one order of magnitude stronger than in the $5 \mathrm{Co}, \mathrm{N}-\mathrm{TiO}_{2}$ and $10 \mathrm{Co}, \mathrm{N}-\mathrm{TiO}_{2}$. It has been suggested that this EPR spectrum arises from trivalent titanium ions located at orthorhombic symmetry sites near the surface [33-35]. The g-factors and linewidths have very similar values for all three investigated samples $\left(\mathrm{g}_{1}=1.948(1), \mathrm{g}_{2}=1.959(3)\right.$ and $\left.g_{3}=1.949(3)\right)$, similar to ones reported in the literature [36].

The FMR spectra for all $(\mathrm{nCo}, \mathrm{N})-\mathrm{TiO}_{2}$ nanocomposites could be very well fitted by using four lines described by the Callen function (Fig. 2). 


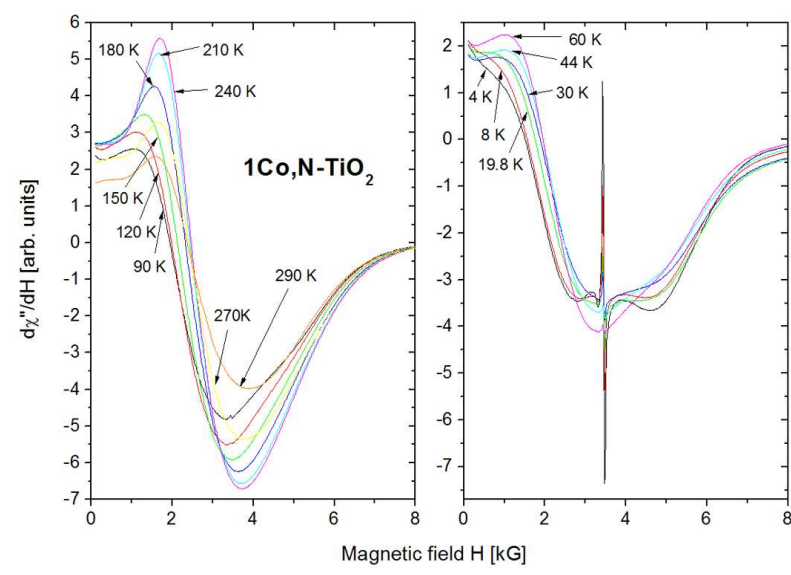

(a)

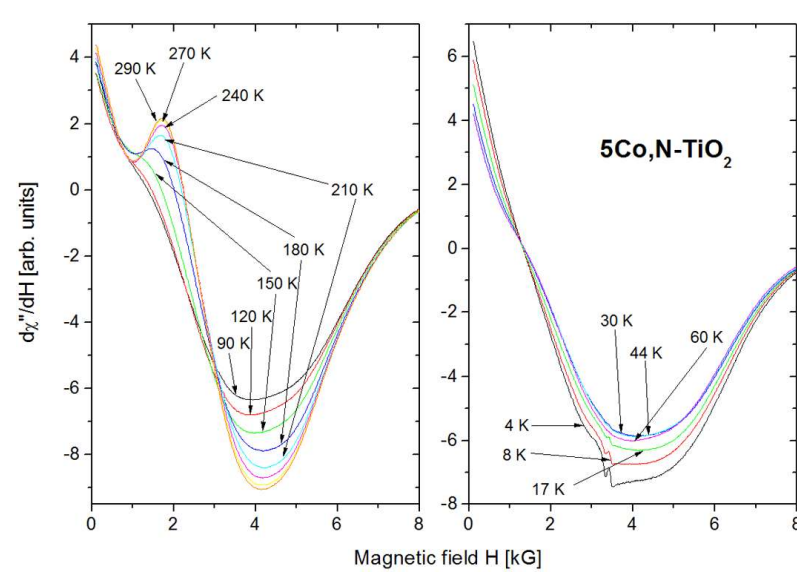

(b)

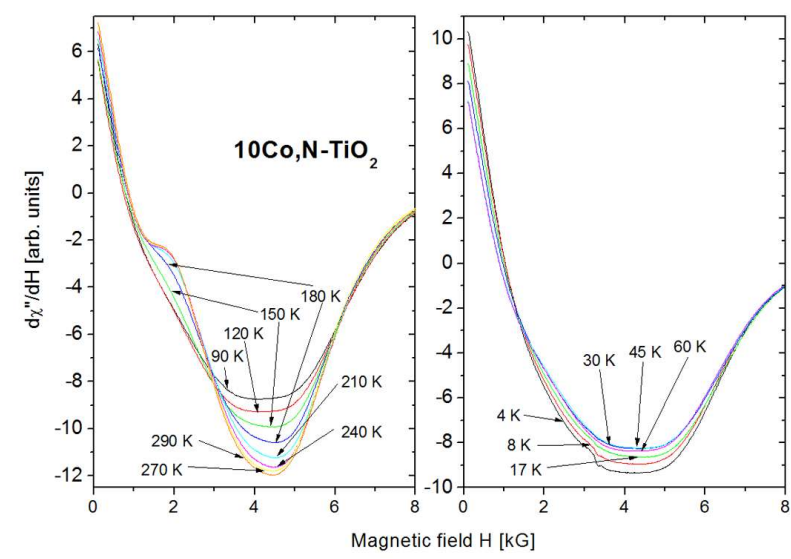

(c)

Fig. 1. The FMR/EPR spectra of (a) $1 \mathrm{Co}, \mathrm{N}-\mathrm{TiO}_{2}$, (b) $5 \mathrm{Co}, \mathrm{N}-\mathrm{TiO}_{2}$, and (c) $10 \mathrm{Co}, \mathrm{N}-\mathrm{TiO}_{2}$ nanocomposites at different temperatures. Right panels present spectra in the low temperature range $(\mathrm{T}<70 \mathrm{~K})$, left panels in the high temperature range $(\mathrm{T}>70 \mathrm{~K})$.
Attempts to fit the observed spectra with a smaller number of components (two or three) or by using other lineshape functions (Lorentz, Gauss, Gilbert, Landau-Lifshitz) were totally unsatisfactory. The following equation of the Callen function was used (it is appropriate in case of the linear polarization of the microwave field) [37, 38]:

$$
\begin{aligned}
I(H) \propto & \left\{H _ { 0 } ^ { 2 } \left[\left(H_{0}^{2}+\Delta_{B}^{2}\right)\left(H^{2} \Delta_{B}+2 H_{0}|H| \delta_{B}\right)\right.\right. \\
& \left.\left.+H_{0}^{2}\left(H_{0}^{2}+\delta_{B}^{2}\right) \Delta_{B}\right]\right\} /\left\{\left[\left(H-H_{0}\right)^{2} H_{0}^{2}\right.\right. \\
& \left.+\left(|H| \Delta_{B}+H_{0} \delta_{B}\right)^{2}\right]\left[\left(H+H_{0}\right)^{2} H_{0}^{2}\right. \\
& \left.\left.+\left(|H| \Delta_{B}+H_{0} \delta_{B}\right)^{2}\right]\right\}
\end{aligned}
$$

where $\mathrm{H}_{0}$ is the intrinsic resonance field, $\Delta_{\mathrm{B}}$ is the linewidth connected with relaxation of the LandauLifshitz (LL) type, and $\delta_{\mathrm{B}}$ is the linewidth connected with the Bloch-Bloembergen (BB) relaxation. Under certain circumstances the LL relaxation can be identified with the longitudinal (spinlattice) and the BB type with the transverse (spinspin) relaxations. The results of fittings for the three studied nanocomposites are presented in Fig. 2 by solid lines. In Fig. 3, as an example, four Callen components found by fitting the experimental spectrum of $10 \mathrm{Co}, \mathrm{N}-\mathrm{TiO}_{2}$ sample at $\mathrm{T}=90 \mathrm{~K}$, are presented.

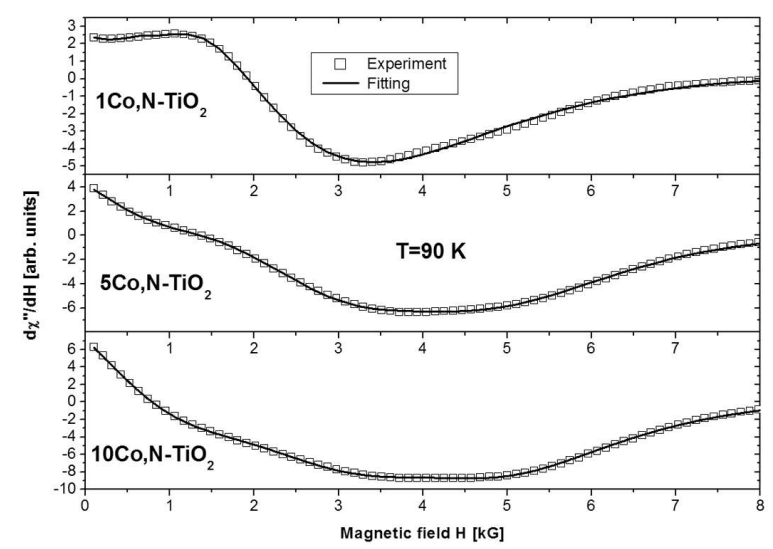

Fig. 2. Experimental (open squares) and fitted (solid lines) magnetic resonance spectra of (a) $1 \mathrm{Co}, \mathrm{N}-$ $\mathrm{TiO}_{2}$, (b) $5 \mathrm{Co}, \mathrm{N}-\mathrm{TiO}_{2}$, and (c) $10 \mathrm{Co}, \mathrm{N}-\mathrm{TiO}_{2}$ nanocomposites at $90 \mathrm{~K}$.

Fig. 4 to Fig. 6 present the temperature dependences of all FMR parameters appearing 


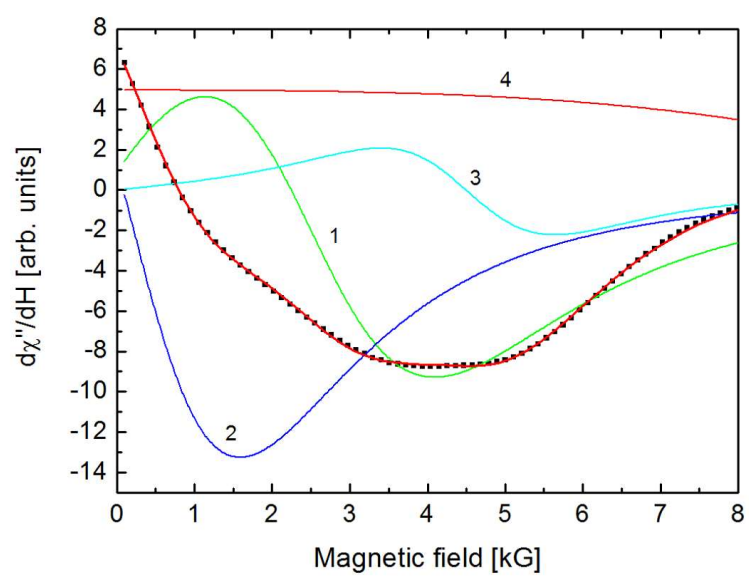

Fig. 3. Experimental FMR spectrum of $10 \mathrm{Co}, \mathrm{N}-\mathrm{TiO}_{2}$ sample at $\mathrm{T}=90 \mathrm{~K}$ (open squares) and fitted four components (solid lines designated 1 to 4 ).

in equation 1, i.e. the resonance field, two types of linewidths (referred to BB and LL relaxations), and the peak-to-peak amplitude. We assume that the four Callen-type components arise from only two types of magnetic centers (two components arising from a single center). One magnetic center is designated as A, the other by letter B. These two components for a single magnetic center are due to magnetic anisotropy of this center and thus could be identified as parallel and perpendicular components with respect to the applied external magnetic field. To identify which components ( 1 to 4 ) belong to the same spin system (A or B), two factors were taken into account: relative intensity of each component (the intensity of the perpendicular component is expected to be bigger than the parallel one due to geometrical circumstances) and consistency of the temperature dependence of its spectral parameters, most importantly the integrated intensity. It was deduced that components 1 and 2 belong to the same magnetic center (center designated as B) and components 3 and 4 to the other center (designated as A). The resonance fields displayed rather insignificant change with temperature, in contrast to materials containing small concentration of magnetic agglomerates in a weakly correlated spin system [31, 39].

Assuming that the magnetic anisotropy field, $\mathrm{H}_{\text {anis }}$, could be evaluated as the difference between

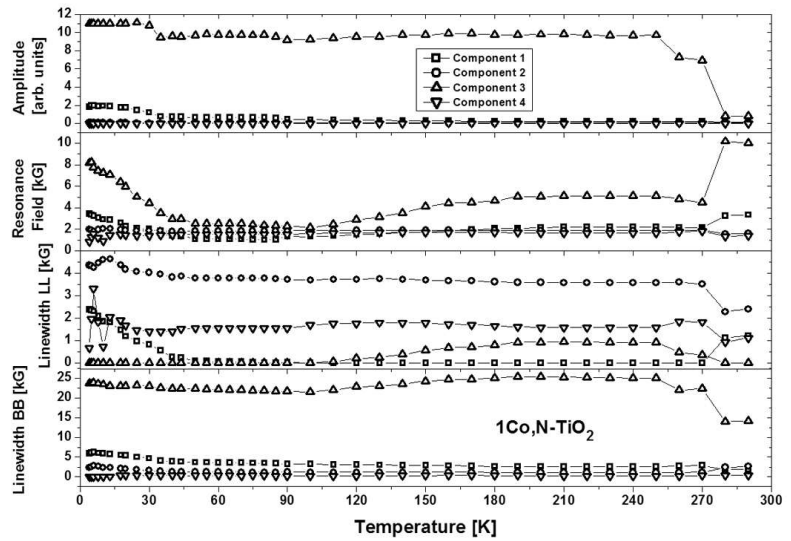

Fig. 4. Temperature dependence of FMR parameters (amplitude, resonance field, two types of linewidths) for Callen-type shape components obtained from fittings in $1 \mathrm{Co}, \mathrm{N}-\mathrm{TiO} 2$ nanocomposite.

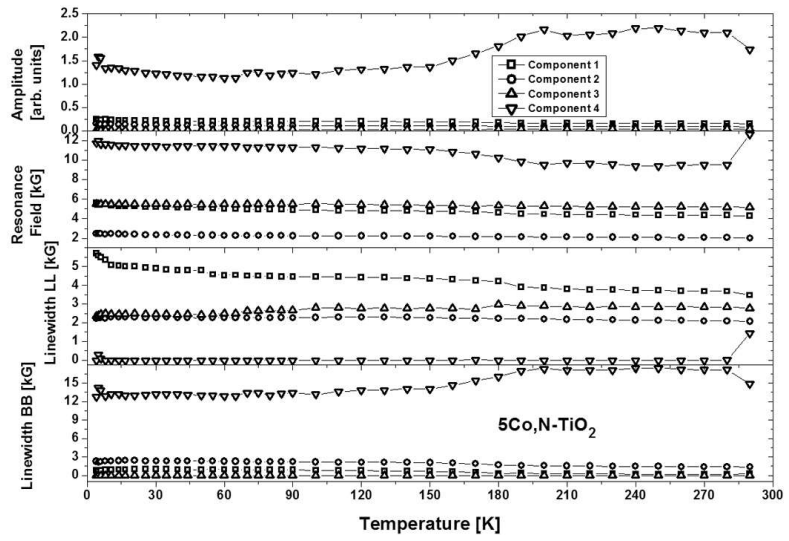

Fig. 5. Temperature dependence of FMR parameters (amplitude, resonance field, two types of linewidths) for Callen-type shape components obtained from fittings in $5 \mathrm{Co}, \mathrm{N}-\mathrm{TiO}_{2}$ nanocomposite.

the resonance fields of two Callen components belonging to the same center, $\mathrm{H}_{\mathrm{anis}} \sim[\mathrm{H}(\mathrm{j})-\mathrm{H}(\mathrm{i})]$, the following values have been obtained and are listed in Table 1. At low temperature $(5 \mathrm{~K})$, the magnetic anisotropy of the center designated as A has almost the same value in all three nanocomposites, while for the second center (center B) the maximum value of anisotropy is found for the $5 \mathrm{Co}, \mathrm{N}-\mathrm{TiO}_{2}$ and $10 \mathrm{Co}, \mathrm{N}-\mathrm{TiO}_{2}$ nanocomposites (Table 1$)$. At high temperature $(270 \mathrm{~K})$, 


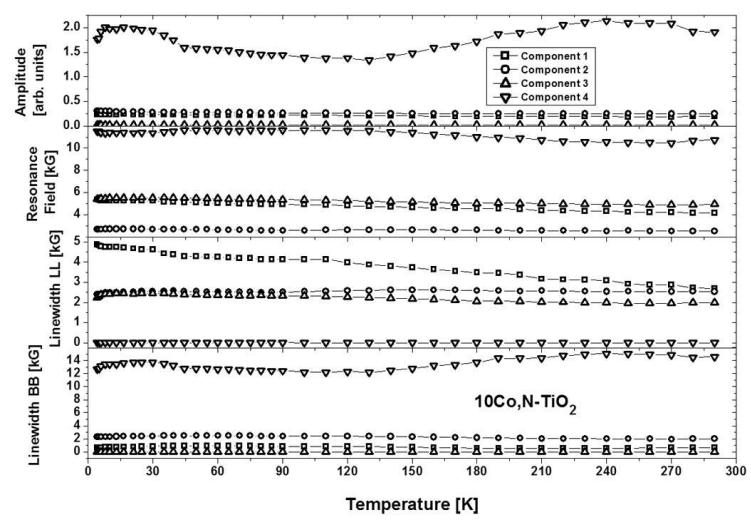

Fig. 6. Temperature dependence of FMR parameters (amplitude, resonance field, two types of linewidths) for Callen-type shape components obtained from fittings in $10 \mathrm{Co}, \mathrm{N}-\mathrm{TiO}_{2}$ nanocomposite.

the magnetic anisotropy of center A increases with the increase of cobalt concentration, but for center B a maximum value of anisotropy is reached for $5 \mathrm{Co}, \mathrm{N}-\mathrm{TiO}_{2}$ sample. With decreasing temperature the value of $\mathrm{H}_{\text {anis }}$ increases in the $5 \mathrm{Co}, \mathrm{N}-\mathrm{TiO}_{2}$ nanocomposite (33\% for center $\mathrm{A}$ and $20 \%$ for center $\mathrm{B}$ ) and changes only slightly in $10 \mathrm{Co}, \mathrm{N}-\mathrm{TiO}_{2}$. In comparison with the $(\mathrm{nFe}, \mathrm{N})-\mathrm{TiO}_{2}$ nanocomposites the magnetic anisotropy in $(\mathrm{nCo}, \mathrm{N})-\mathrm{TiO}_{2}$ is smaller and its temperature dependence is weaker [40]. The XRD measurement showed the existence of cobalt residues in the $5 \mathrm{Co}, \mathrm{N}-\mathrm{TiO}_{2}$ and $10 \mathrm{Co}, \mathrm{N}-\mathrm{TiO}_{2}$ nanocomposites [20]. Thus, it is very probable that the magnetic anisotropy, which is almost the same in all three samples for center A, is derived from metallic cobalt nanoparticles. Thus, we assume that center $\mathrm{A}$ is formed by metallic cobalt nanoparticles dispersed in $\mathrm{TiO}_{2}$ matrix. In consequence, it can be concluded that metallic cobalt, which was not seen by XRD method in $1 \mathrm{Co}, \mathrm{N}-\mathrm{TiO}_{2}$ nanocomposite, is also present in that sample. Magnetic center B is most probably related to the clusters of $\mathrm{Co}^{2+}$ ions (magnetic polarons) that entered substitutionally in the $\mathrm{TiO}_{2}$ crystal structure for $\mathrm{Ti}^{4+}$ ions.

Like in case of iron modified titanium dioxide nanocomposites, the linewidths of all four components in $\mathrm{nCo}, \mathrm{N}-\mathrm{TiO}_{2}$ samples depend weakly on temperature (Fig. 4 to Fig. 6) [40]. In the $1 \mathrm{Co}, \mathrm{N}-$ $\mathrm{TiO}_{2}$ nanocomposite one of the component (designated as 1 in Fig. 4 to Fig. 6) displayed a strong variation of the linewidth connected with relaxation of the LL type at temperature below $30 \mathrm{~K}$. In the $5 \mathrm{Co}, \mathrm{N}-\mathrm{TiO}_{2}$ and $10 \mathrm{Co}, \mathrm{N}-\mathrm{TiO}_{2}$ nanocomposites an increase in the LL linewidth with decreasing temperature of the same component was also observed. Certain fluctuations in linewidth were observed for component 1 produced by the BB relaxation. For the $1 \mathrm{Co}, \mathrm{N}-\mathrm{TiO}_{2}$ nanocomposite the line broadening is the biggest for the magnetic center $\mathrm{A}$, where relaxation is dominated by the $\mathrm{BB}$ type at low temperatures. In the $5 \mathrm{Co}, \mathrm{N}-\mathrm{TiO}_{2}$ nanocomposite at low and high temperature the linewidth broadening is mainly due to the $\mathrm{BB}$ relaxation. In the case of $10 \mathrm{Co}, \mathrm{N}-\mathrm{TiO}_{2}$ nanocomposite at high temperatures the broadening is dominated by the LL relaxation and at lower temperature by the BB relaxation. In such complex magnetic system the processes associated with the mechanism of the BB relaxation (spin-spin) play an important role at high temperatures and strongly depend on the concentration of magnetic centers. The reorientation processes of the spin system could involve essential changes in the dipole-dipole interaction which may play an important role in the relaxation processes.

Just as was done previously for $(\mathrm{nFe}, \mathrm{N})-\mathrm{TiO}_{2}$ nanocomposites, we have also calculated the temperature dependence of the integrated intensity, $I_{\text {int }}=A_{p p}\left(\Delta H_{p p}\right)^{2}$, where $A_{p p}$ is the peak-to-peak amplitude and $\Delta \mathrm{H}_{\mathrm{pp}}$ is the peak-to-peak linewidth, for all investigated $\left(\mathrm{nCo}, \mathrm{N}-\mathrm{TiO}_{2}\right)$ samples [40]. The integrated intensity is proportional to the magnetic susceptibility (at microwave frequency) of magnetic species participating in magnetic resonance. As an example, Fig. 7 shows the temperature dependence of the integrated intensity of centers $\mathrm{A}$ and $\mathrm{B}$ measured for $5 \mathrm{Co}, \mathrm{N}-\mathrm{TiO}_{2}$ nanocomposite. It is clearly seen that the temperature behavior of both centers is quite different. The integrated intensity of center A (metallic Co nanoparticles) diminishes with temperature decrease, while center $\mathrm{B}$ (substitutional $\mathrm{Co}^{2+}$ ions) increases the intensity with lowering temperature, showing behavior similar to paramagnetic entities. 
Table 1. Anisotropy fields for centers A and B at high $(270 \mathrm{~K})$ and low temperature (5 K).

\begin{tabular}{ccccc}
\hline \multirow{2}{*}{ Nanocomposite } & \multicolumn{2}{c}{ Temperature 270 K } & \multicolumn{2}{c}{ Temperature 5 K } \\
\cline { 2 - 5 } & $\begin{array}{c}\text { Anisotropy field } \\
\text { of center A [kG] }\end{array}$ & $\begin{array}{c}\text { Anisotropy field } \\
\text { of center B [kG] }\end{array}$ & $\begin{array}{c}\text { Anisotropy field } \\
\text { of center A [kG] }\end{array}$ & $\begin{array}{c}\text { Anisotropy field } \\
\text { of center B [kG] }\end{array}$ \\
\hline \hline $1 \mathrm{Co}, \mathrm{N}-\mathrm{TiO}_{2}$ & 3 & $\sim 0$ & 6 & 2 \\
$5 \mathrm{Co}, \mathrm{N}-\mathrm{TiO}_{2}$ & 4.5 & 2.5 & 6 & 3 \\
$10 \mathrm{Co}, \mathrm{N}-\mathrm{TiO}_{2}$ & 5.5 & 2 & 6 & 3 \\
\hline
\end{tabular}

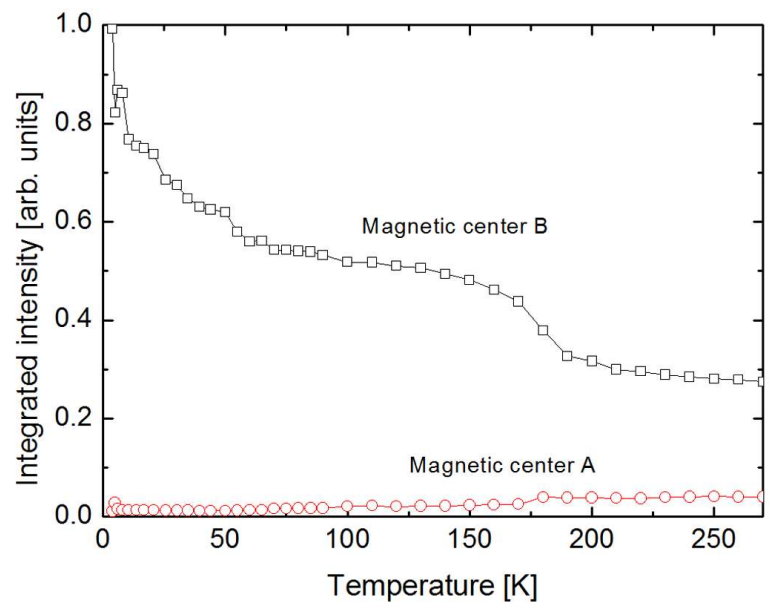

Fig. 7. Temperature dependence of the integrated intensity of center A (open circles) and B (open squares) in $5 \mathrm{Co}, \mathrm{N}-\mathrm{TiO}_{2}$ nanocomposite.

To find explanation of this very different temperature behavior of $\mathrm{I}_{\text {int }}$ of $\mathrm{A}$ and $\mathrm{B}$ centers, it would be appropriate to recall recent DC magnetization studies (in ZFC and FC modes) of these samples [41]. It was shown that at RT and below, the main part of the nanocomposite was in a blocked FM state, because the blocking temperature $T_{B}$ was higher than RT. Given this fact, it is surprising that magnetic resonance spectra were registered below RT for our (nCo, $\left.\mathrm{N}-\mathrm{TiO}_{2}\right)$ samples, since conventional EPR spectrometers should not be able to register any signal from FM samples (the resonance line should be broadened beyond the range of typical EPR spectrometer). The plausible explanation of the factual existence of the observed spectra can be offered if it is assumed that the SPM state is present in a part of studied samples or/and the paramagnetic clusters of Co ions in $\mathrm{TiO}_{2}$ matrix exist. Both the explanations presume that the observed magnetic resonance spectra of $\left(\mathrm{nCo}, \mathrm{N}-\mathrm{TiO}_{2}\right)$ samples are formed by only a small part of the total cobalt ions. This is not in conflict with $\mathrm{ZFC/FC} \mathrm{magnetization} \mathrm{measurements} \mathrm{[41].}$

The supposition of the SPM phase of FM cobalt nanoparticles (center A) explains plausibly the diminishing of $\mathrm{I}_{\text {int }}$ with temperature decrease if only the spread of nanoparticle sizes is assumed. The blocking temperature $T_{B}$, separating the blocked (below $\mathrm{T}_{\mathrm{B}}$ ) and unblocked (above $T_{B}$ ) FM nanoparticles, depends on the size of the nanoparticle, $T_{B} \sim K \cdot V$, where $K$ is the effective uniaxial anisotropy constant and $\mathrm{V}$ is the volume of the nanoparticle [42]. From this expression follows that the smaller the particle, the lower the blocking temperature. Thus, at a specific temperature (below $\mathrm{RT}$ ) only the FM nanoparticles having $T_{\mathrm{B}}$ smaller than that specific temperature would participate in formation of SPM spectrum and thus be observed by EPR spectroscopy. As the number of progressively smaller nanoparticles is diminishing, the $\mathrm{I}_{\mathrm{int}}$ would be decreasing with lowering temperature. In consequence, the functional dependence of $\mathrm{I}_{\text {int }}$ on temperature reflects a fragment of the nanoparticles sizes distribution function (its low sizes wing).

The presence of the paramagnetic Co clusters in $\mathrm{TiO}_{2}$ matrix may explain the $\mathrm{I}_{\text {int }}(\mathrm{T})$ dependence of the $\mathrm{B}$ type center (Fig. 7). FM state in $\left(\mathrm{nCo}, \mathrm{N}-\mathrm{TiO}_{2}\right)$ nanoparticles due to an internal cause is the best explained by BMP model in which an electron trapped in oxygen vacancy bounds two neighboring $\mathrm{Co}^{2+}$ ions. If the number of such magnetic polarons is large and the percolation threshold is crossed, the global FM state is achieved. In this situation, no magnetic resonance signal is expected 
to be visible in EPR spectrum. However, if in a particular nanoparticle no percolation threshold is reached - due to lower than average concentration of dopants or not so high number of oxygen vacancies - no FM state will be formed. In this case only paramagnetic cobalt clusters will exist and they will produce the observed magnetic resonance spectrum with a characteristic paramagnetic thermal behavior. This explains the increase of the integrated intensity of the $\mathrm{B}$ center during temperature decrease.

\section{Conclusions}

The magnetic resonance study of three comodified $(\mathrm{nCo}, \mathrm{N})-\mathrm{TiO}_{2}$ nanocomposites showed the existence of rather complex and interesting magnetic properties of these samples. Analysis of the magnetic resonance spectra revealed the existence of magnetic centers of two types: one derived from metallic cobalt nanoparticles dispersed in $\mathrm{TiO}_{2}$ matrix and the other involving substitutional cobalt ions in the $\mathrm{TiO}_{2}$ lattice. Additionally, the EPR spectrum of trivalent titanium ions was observed at low temperature and was especially intense in case of the $1 \mathrm{Co}, \mathrm{N}-\mathrm{TiO}_{2}$ nanocomposite. The relaxation of the $\mathrm{LL}$ and $\mathrm{BB}$ types played an important role at high temperatures and the latter was dominant at low temperature. Analysis of the integrated intensity demonstrated that the SPM spectrum of metallic cobalt at RT and lower temperature arises from smaller than average in size Co nanoparticles. Paramagnetic signal registered in $(\mathrm{nCo}, \mathrm{N})-\mathrm{TiO}_{2}$ nanocomposites originates from those nanoparticles in which the concentration of magnetic polarons is below the percolation threshold.

\section{References}

[1] Schneider J., Matsuoka M., Takeuchi M., Zhang J., Horiuchi Y., ANPo M., BahnemanN D.W., Chem. Rev., 114 (2014), 9919.

[2] Yates H.M., Nolan M.G., Sheel D.W., Pemble M.E., J. Photochem. Photobiol. A, 179 (2006), 213.

[3] Thompson T.L., Yates JR. J.T., Chem. Rev., 106 (2006), 4428.

[4] Hashimoto K., Irie H., Fujishima A, Jpn. J. Appl. Phys., 44 (2005), 8269.
[5] Stepanov A.L., Rev. Adv. Mater. Sci., 30 (2012), 150.

[6] Zaleska A., Recent Pat. Eng., 2 (2008), 157.

[7] Matsumoto Y., Murakami M., Shono T., Hasegawa T., Fukumura T., Kawasaki M., AhMet P., Chikyow T., Koshihara S., Koinuma H., Science, 291 (2001), 854.

[8] Dietl T., Ohno H., Matsukura F., Cibert J., FERRAND D., Science, 287 (2000), 1019.

[9] Sato K., Katayama-Yoshida H., Jpn. J. Appl. Phys., 39 (2000), L555.

[10] Coey J.M.D., Venkatesan M., Fitzgerald C.B., Nat. Mater., 4 (2005), 173.

[11] Janisch R., Gopal P., Spaldin N.A., J. Phys.: Condens. Mater., 17 (2005), R657.

[12] Li X.L., Qi S.F., Jiang F.X., QUAn Z.Y., XU X.H., Sci. China-Phys. Mech. Astron., 56 (2013), 111.

[13] Griffin Roberts K., Varela M., Rashkeev S., PAntelides S.T., PENNYCOOK S.J., KRISHNAN K.M., Phys. Rev. B, 78 (2008), 014409.

[14] Yamada Y., Fukumura T., Ueno K., Kawasaki M., Appl. Phys Lett., 99 (2011), 242502.

[15] Mohanty P., Mishra N.C., Choudhary R.J., BANERJEE A., Shripathi T., LALla N.P., ANNapoorni S., Chandana R, J. Phys. D Appl. Phys., 45 (2012), 32530.

[16] Tian J., Gao H., Kong H., Yang P., Zhan W., Chu J., Nanoscale Res. Lett., 8 (2013), 533.

[17] Santara B., Pal B., Giri P.K., J. Appl. Phys., 110 (2011), 114322.

[18] Nakai I., SASAno M., InUi K., KorekaWa T., IshiJima H., КАтOH H., J. Korean Phys. Soc., 63 (2013), 532.

[19] Kaushik A., Dalela B., Kumar S., Alvi P.A., Dalela S., J. Alloy. Compd., 552 (2013), 274.

[20] Kim J.Y., PARK J.H., PARK B.G., NOH H.J., OH S.J., YANG J.S., Kim D.H., BU S.D., NOH T.W., LiN H.J., Hsieh H.H., Chen C.T., Phys. Rev. Lett., 90 (2003), 017401.

[21] Shinde S.R., Ogale S.B., Sarma S.D., Simpson J.R., DREW H.D., LOFland S.E., LANCI C., BUBAN J.P., BROWNing N.D., KUlKaRni V.N., Higgins J., Sharma R.P., Greene R.L., Venkatesan T., Phys. Rev. B, 67 (2003), 115211.

[22] Kaspar T.C., Droubay T., McCready D.E., Nachimuthu P., Heald S.M., Wang C.M., Lea A.S., Shutthanandan V., Chamber S.A., Toney M.F., J. Vac. Sci. Technol. B, 24 (2006), 2012.

[23] Xu J., Shi S., Li L., Zhang X., Wang Y., Chen X., WAng J., Lv L., Zhang F., Zhong W., J. Appl. Phys., 107 (2010), 053910.

[24] Rashad M.M., Elsayed E.M., Al-Kotb M.S., Shalan A.E., J. Alloy. Compd., 581 (2013), 71.

[25] Huang C., LiU X., Kong L., Lan W., Su Q., WANG Y., Appl. Phys. A, 87 (2007), 781.

[26] Sadanandam G., Lalitha K., Kumari V.D., SHANKAR M.V., SUbRahMANYAM M., Int. J. Hydrogen Energ., 38 (2013), 9655. 
[27] Guskos N., Zolnierkiewicz G., Guskos A., TyPeK J., Berczynski P., Dolat D., Mozia S., Aidinis K., Morawski A.W., Nukleonika, 60 (2015), 411.

[28] Dolat D., Mozia S., Wrobel R. J., MoszynSki D., Ohtani, B., Guskos N., Morawski A.W., Appl. Catal. B-Environ., 162 (2015), 310.

[29] Guskos N., Zolnierkiewicz G., Guskos A., Typek J., Berczynski P., Dolat D., Mozia S., MoraWs KI A.W., Magnetic Resonance Study of Nickel and Nitrogen Co-modified Titanium Dioxide Nanocomposites, in: BonCA J., KRUCHININ S. (Eds.), NATO Science for Peace and Security Series C: Environmental Security, Nanotechnology in the Security Systems, Springer, Dordrecht, 2015, p. 33.

[30] Guskos N., TyPeK J., Maryniak M., NARkiewicz U., KuCharewicz I., Wrobel R., Mater. Sci.-Poland, 23 (2005), 1001.

[31] Bodziony T., Guskos N., TYPEK J., Roslaniec Z., NARKIEWICZ U., Maryniak M., Mater. Sci.-Poland, 23 (2005), 1055.

[32] NARKiewicz U., ARABCZYK W., PeŁech I., Guskos N., TyPeK J., MARYNiak M., Wozniak M.J., Matysiak H., Kurzydlowski K.J., Mater. Sci.-Poland, 24 (2006), 1067.

[33] Hurum D.C., Agrios A.G., Gray K.A., Rajh T., Thurnauer M.C., J. Phys. Chem. B, 107 (2003), 4545.

[34] Kumar C.P., Gopal N. O., Wang T. C., Wong M.S., Ke S.C., J. Phys. Chem. B, 110 (2006), 5223.

[35] Ribbens S., Caretti I., Beyers E., Zamani S., Vinck E., Van Doorslaer S., Cool P., J. Phys. Chem. C, 115 (2011), 2302.
[36] Dolat D., Moszynski D., Guskos N., Ohtani B., Morawski A.W., Appl. Surf. Sci., 266 (2013), 410.

[37] KliaVA J., Electron Magnetic Resonance of Nanoparticles: Superparamagnetic Resonance, in: GUBIN S.P (Ed.), Magnetic nanoparticles, Wiley-VCH, Weinheim, 2009, p. 255.

[38] Helminiak A., ARAbczyK W., ZolNIERKIEWICZ G., Guskos N., TYPEK J., Rev. Adv. Mat. Sci., 29 (2011), 166.

[39] Guskos N., Likodimos V., Glenis S., MaryNIAK M., BARAN M., SZYMCZAK R., RoslanieC Z., Kwiatkowska M., Petridis D., J. Nanosci. Nanotech., 8 (2008), 2127.

[40] Guskos N., Glenis S., Zolnierkiewicz G., Guskos A., TypeK J., Berczynski P., Dolat D., Grzmil B., Ohtani B., Morawski. A.W., J. Alloy. Compd., 606 (2014), 32.

[41] Guskos N., TyPeK J., ZOLnierkiewicZ G., Diamantopoulou A., Mozia S., Morawski A.W., Magnetic Properties of Cobalt and Nitrogen Co-modified Titanium Dioxide Nanocomposites, in: Bonca J., KRUCHInIN S. (Eds.), NATO Science for Peace and Security Series C: Environmental Security, Nanotechnology in the Security Systems, to be published in 2016.

[42] Knobel M., Nunes W.C., Socolovsky L.M., De Biasi E., VARgas J.M., Denardin J.C., J. Nanosci. Nanotech., 8 (2008), 2836.
Received 2015-03-09 Accepted 2016-02-01 